\title{
PERSPECTIVAS Y RETOS DE LA EDUCACIÓN. TOMO ${ }^{50}$
}

Guadalupe Aleida Valenzuela Miranda; Miguel Arturo Morales Zamorano; Adria Velia González Beltrones; Ana Lilia Banda Castro; Ana Valenzuela Mendívil; Francisca Belinda Márquez Ulloa; José Saúl Hernández López; Yadira Jiménez Ramos; Alipia Avendaño Enciso; Gilberto Vargas Mendía; Ramiro Ávila Godoy.

\section{Iván de Jesús CERVANTES RASCÓN Estudiante de la Licenciatura en Derecho Universidad de Sonora Ivande.cervantesra@correoa.uson.mx}

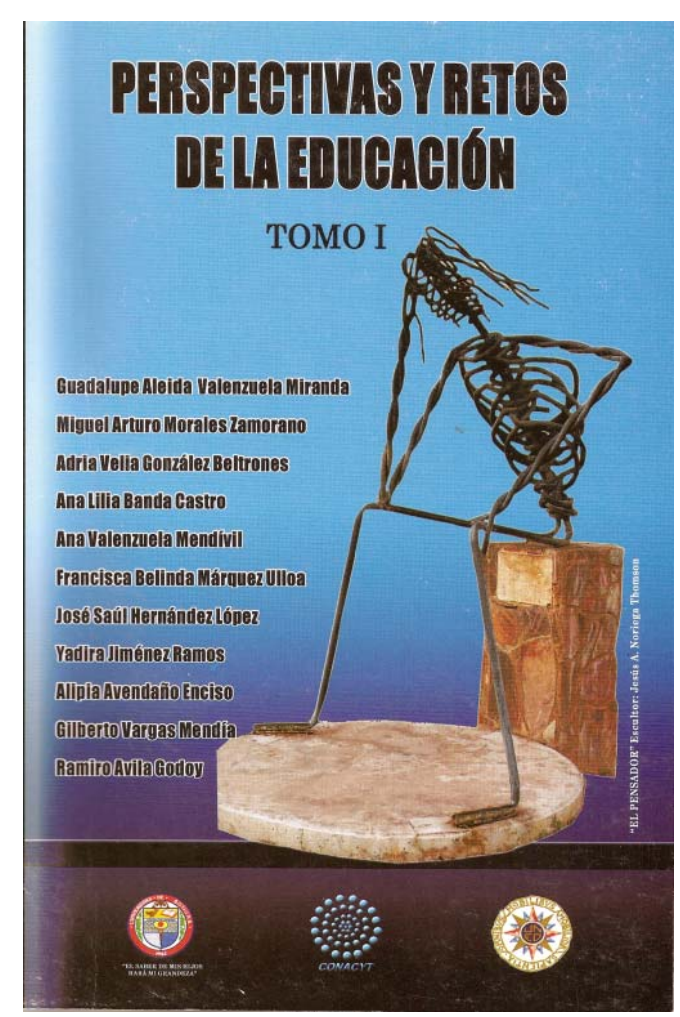

Es bien sabido que la educación universitaria es un elemento invaluable para el desarrollo de un país, de hecho podría decirse que entre más universidades tenga un país, más desarrollado llegara a ser. Sin embargo, es de todos conocidos que, principalmente en los países en desarrollo, la universidad se enfrenta con graves problemas como pueden ser falta de presupuesto, alejamiento de la sociedad (De donde proviene y donde invariablemente debe de volcar sus avances), planes de estudio retrógrados, una ausencia las nuevas tecnologías de la información y la comunicación en su quehacer diario, egresados $\sin$ un pensamiento humanista $y$ cosmopolita, etc. Todos esos problemas, y algunos más, encuentran posibles soluciones en el presente libro.

Sustentado en los grados académicos, la amplia práctica docente y la larga experiencia en investigación de sus autores, el libro se enfoca en los siguientes temas: Modelo de Creatividad para Orientar las Innovaciones Curriculares en Educación Superior; Prospectiva Participativa Ciudadanas en Redes de Colaboración en Sistemas Escolares; Hacia una Estrategia en reingeniería educativa; Tendencias actuales del Derecho; La Enseñanza del Derecho con apoyo a los Tics; ¿Es necesario educarnos en la búsqueda de un proceso de calidad de vida?; ¿El Sistema Educativo Mexicano en Crisis?; Problemas, retos y perspectivas en la Universidad de Sonora; Alternativa de evaluación de aprendizaje de un espacio educativo y seguimiento del uso de la plataforma electrónica; Estilos de aprender y estilos de enseñanza en las Instituciones Educativas; Estudio de Casos; Tecnología de redes; educación virtual y formación de profesores de matemáticas. Todo lo anterior como el resultado de una amplia investigación de alta calidad.

Aunque a simple vista puede apreciarse como un contenido completo, en su lectura se descubre que este es sumamente amplio, puesto que otorga al lector una visión amplia de la educación universitaria en México desde la década de los 70’s hasta la actualidad, otorga soluciones viables a las

${ }^{50}$ Hermosillo, Sonora, México, 2007. Editorial UNISON-CONACYT (182 páginas) ISBN: 970-689-373-3 
problemáticas actuales, es decir, propone un replanteamiento completo del sistema educativo universitario. Se trata de un texto básico para todos los relacionados con el mundo de la educación, desde los estudiantes de primer semestre de cualesquier carrera, hasta los rectores de las más grandes universidades de nuestro país.

Desde esta perspectiva, materialmente el libro es sencillo, con un lenguaje ameno que permite una pronta comprensión. Su portada llama la atención debido a una curiosa escultura moderna que se encuentra colocada en la Universidad de Sonora, el nombre con el que el artista bautizo a su creación no podría ser más acorde: "El Pensador".

Para finalizar, se ha abordado una problemática educativa formulando una respuesta abierta a todas aquellas personas interesadas en innovar, en educación superior. En definitiva, la obra es una valiosa aportación universitaria y convierte a sus autores en investigadores del pensamiento, responsables en cada capítulo con una dilatada experiencia en la docencia e investigación, y con un vasto campo de publicaciones especializadas. 